\title{
Entre a fronteira do aprender e o fracasso escolar no Transtorno de Déficit de Atenção e Hiperatividade
}

\section{Between the frontier of learning and school failure in Attention Deficit Hyperactivity Disorder}

DOI: $10.46814 / 1 a j d v 3 n 3-013$

Recebimento dos originais: 01/05/2021

Aceitação para publicação: 30/06/2021

\section{Elizane Franchi Pelligrini}

Mestrado em Ciências da Educação, UNIGRAN

Rede Municipal de Ensino de Marapoama - Colégio Maria Educadora - Sistema Objetivo

R. Cincinato Braga, 1060 - Tiberio, Itajobi - SP, 15840-000

E-mail: elizanefpelligrini@gmail.com

\author{
Alessandra Cury Nesso \\ Mestrado em Ciências da Educação, UNIGRAN \\ Rede Municipal de Ensino de Itajobi - Colégio Maria Educadora - Sistema Objetivo \\ R. Cincinato Braga, 1060 - Tiberio, Itajobi - SP, 15840-000 \\ E-mail: alenesso@hotmail.com \\ Daniela Cristina Calera Berengel \\ Mestrado em Ciências da Educação, UNIGRAN \\ Rede Municipal de Ensino de Itajobi - Colégio Maria Educadora - Sistema Objetivo \\ R. Cincinato Braga, 1060 - Tiberio, Itajobi - SP, 15840-000 \\ E-mail: dani_calera@hotmail.com \\ Vilma Aparecida Marim Bolssone \\ Mestrado em Ciências da Educação, UNIGRAN \\ Colégio Maria Educadora - Sistema Objetivo \\ R. Cincinato Braga, 1060 - Tiberio, Itajobi - SP, 15840-000 \\ E-mail: objetivoitajobi@ hotmail.com \\ Valéria André dos Santos \\ Mestre em Letras, PROFLETRAS/UNEMAT \\ Escola Estadual "Rui Barbosa" \\ Rua Arnaldo Mota, - Centro, Glória D'Oeste - MT, 78293-000 \\ E-mail: valeriasantos@ unemat.br \\ Leonila Santos Almeida Sasso \\ Pesquisadora Independente \\ E-mail: leosaalm988@gmail.com
}

\section{Júlio César André}

Doutor em Ciências, Faculdade de Medicina de Ribeirão Preto - USP

Centro de Estudos e Desenvolvimento de Educação em Saúde da Faculdade de Medicina de São José do Rio Preto - CEDES/FAMERP

Av. Brigadeiro Faria Lima, - 5416 - Vila São Pedro, São José do Rio Preto - SP, 15.090-000 
E-mail: julio.andre@ famerp.br

\title{
RESUMO
}

A escolarização da criança com Transtorno de Déficit de Atenção e Hiperatividade (TDAH) ainda constitui um grande desafio, visto que além das dificuldades em responder às demandas acadêmicas em termos de aprendizagem, o padrão de interações sociais, com os colegas e os professores, também impõe obstáculos para a participação efetiva em todas as atividades do ambiente escolar. Levantar fatores que levam as crianças com TDAH a não aprenderam na escola foi o objetivo deste estudo longitudinal retrospectivo do tipo coorte histórico que utilizou a revisão de 49 prontuários, com 3 unidades de análise: dados pessoais e socioeconômicos, dados de formação educacional e dados específicos contendo questões dicotômicas de resposta única. Os dados mostrados aqui para os portadores de TDHA da amostra são: $4,1 \%$ de histórico de adoção, $2 \%$ de existência de patologia de base, $22,4 \%$ de histórico de drogadição para o pai e 10,2\% para a mãe. Dado discordante da literatura: $87,7 \%$ de não reprovação. É primordial buscar constantemente conhecer mais acerca desse transtorno, tanto por parte dos profissionais da educação quanto da família, desde o diagnóstico até o tratamento, de forma a contribuir para oferecer, no âmbito escolar, um ensino significativo para os portadores de TDAH.

Palavras-chave: TDHA, ensino fundamental, fatores sociodemográficos, história familiar.

\begin{abstract}
The schooling of children with Attention Deficit Hyperactivity Disorder (ADHD) is still a great challenge, since in addition to the difficulties in responding to academic demands in terms of learning, the pattern of social interactions, with colleagues and teachers, also imposes obstacles to effective participation in all activities in the school environment. Raising factors that lead children with ADHD to not learn at school was the aim of this longitudinal retrospective study of the historical cohort type that used the review of 49 medical records, with 3 units of analysis: personal and socioeconomic data, educational training data and specific data containing dichotomous questions with a single answer. The data shown here, for patients with ADHD in the sample, are: $4.1 \%$ of history of adoption, $2 \%$ of existence of underlying pathology, $22.4 \%$ of history of drug addiction for the father and 10,2\% for the mother. Disagreeing data from the literature: $87.7 \%$ of non-failure. It is essential to constantly seek to know more about this disorder, both on the part of education professionals and the family, from diagnosis to treatment, in order to contribute to offer, in the school context, a meaningful teaching for patients with ADHD.
\end{abstract}

Keywords: ADHD, elementary school, sociodemographic factors, family history.

\section{INTRODUÇÃO}

O Transtorno de Déficit de Atenção e Hiperatividade (TDAH) é um transtorno psíquico que apresenta como principais manifestações desatenção, impulsividade, dificuldade de concentração e hiperatividade de acordo com o Manual Diagnóstico e Estatístico de Doenças Mentais - $5^{\mathrm{a}}$ Edição (DSM-5) (AMERICAN PSYCHIATRIC ASSOCIATION, 2014). É um transtorno psiquiátrico de grande importância em saúde pública, considerando os problemas causados seja na infância, adolescência e na escola; seja na idade adulta e no trabalho; ou em ambas, e nos relacionamentos com os demais. Estima-se que em torno de 5 a $8 \%$ da população infantil mundial e 2,5\% em adultos 
apresente este transtorno (POLANCZYK et al., 2014; AMERICAN PSYCHIATRIC ASSOCIATION, 2014). A falta de diagnóstico e tratamento apropriado acarretam grandes prejuízos à vida da criança e do adulto, nos aspectos profissional, social, pessoal e afetivo. Sem tratamento, outros distúrbios podem associar-se ao quadro, a autoestima fica cada vez mais comprometida e o indivíduo pode se isolar do mundo.

\subsection{TRANSTORNO DE DÉFICIT DE ATENÇÃO E HIPERATIVIDADE (TDAH)}

O TDAH foi descrito pela primeira vez em 1902 pelo pediatra inglês George Still, que observou alterações de comportamento em crianças. Ele acreditava que o fator não era atribuído por problemas educacionais, mas sim por determinantes biológicos. O transtorno vem sendo estudado em vários países e desde 1960 recebeu diversas denominações (SILVA, 2009).

Estudos epidemiológicos mostraram associações entre o TDAH e vários fatores ambientais. Estes incluem principalmente fatores de risco pré e perinatais (estresse materno, tabagismo ou consumo de álcool durante a gravidez, baixo peso ao nascer, prematuridade), toxinas ambientais (organofosforados, bifenilos policlorados, chumbo), condições psicossociais desfavoráveis (privação grave da primeira infância, hostilidade materna) e fatores dietéticos (FARAONE et al., 2015; THAPAR \& COOPER, 2016).

O TDAH é um transtorno de saúde mental e têm três características básicas: a desatenção, a hiperatividade e a impulsividade. Este transtorno tem um grande impacto na vida da criança ou do adolescente e das pessoas com as quais convive (amigos, pais e professores). Pode levar a dificuldades emocionais, de relacionamento familiar e social, bem como a um baixo desempenho escolar (ROHDE \& BENCZIK, 2009).

Segundo o DSM-5 (AMERICAN PSYCHIATRIC ASSOCIATION, 2014) o TDAH é definido através de 18 sintomas que compõe duas dimensões: desatenção e hiperatividade/impulsividade. São considerados com TDAH comprovado os indivíduos que apresentam por um período de seis meses ou mais os principais sintomas como desatenção e hiperatividade/ impulsividade.

A criança hiperativa muitas vezes se sente isolada e separada dos colegas, mas não entende por que é tão diferente. Fica perturbada com suas próprias incapacidades. Sem conseguir concluir as tarefas normais de uma criança na escola ou em casa, a criança hiperativa pode sofrer de estresse, tristeza e baixa autoestima (AMERICAN PSYCHIATRIC ASSOCIATION, 2014).

\subsection{DESEMPENHO ESCOLAR NO TDAH}

Tanto em crianças quanto em adolescentes o TDAH está diretamente relacionado ao baixo desempenho escolar e insucesso acadêmico, rejeição social e altos níveis de conflitos interpessoais. 
Crianças portadoras de TDAH apresentam uma probabilidade significativamente maior de desenvolver transtorno de conduta na adolescência e transtorno de personalidade antissocial quando adultos, aumentando assim as chances de desenvolver transtornos por uso de substâncias e prisão (AMERICAN PSYCHIATRIC ASSOCIATION, 2014).

De acordo com pesquisa realizada por Goldstein \& Goldstein (2009), conclui-se que cerca de 20 a 30\% das crianças com TDAH podem ter problemas de desatenção sem problemas significativos de excesso de atividade ou impulsividade e que tais crianças têm maior probabilidade de desenvolver depressão de ansiedade, de comportamento perturbador e um desempenho escolar mais fraco, tendo maior dificuldade de aprendizagem.

No aprendizado dos alunos com diagnóstico de TDAH, é indispensável entender em que nível operatório eles se encontram, para suas atividades serem ajustadas de acordo com seu desempenho. Esses alunos precisam ser estimulados com brincadeiras, jogos lúdicos e jogos com regras, que ajudam o aluno no convívio social e a saber perder e ganhar. Esses alunos são bem desorganizados, precisam ter uma pessoa que os ajude a se organizarem melhor. Isso cabe ao profissional da área e aos familiares, para darem um tempo maior para se ajustarem em suas atividades. Saber entender o processo de aprendizado desses alunos é muito importante (SILVA, 2020).

\subsection{O PROFESSOR DIANTE DO TDAH}

Poucos professores têm conhecimento sobre o TDAH e muitas vezes uma percepção errônea sobre o transtorno.

Por ser o professor o mediador do conhecimento, ele deve entender exatamente a sua responsabilidade educacional na vida do aluno com TDAH. Segundo a Associação Brasileira de Déficit de Atenção (ABDA):

\footnotetext{
"O professor é um dos grandes observadores de crianças, é quem as conhece como poucos, pois consegue manter o olhar individual, mesmo em meio a uma 'multidão'. Diferente de outros profissionais, ele é um dos poucos que enxerga a criança e o adolescente em sua rotina, na realidade em que ele está inserido." (ASSOCIAÇÃO BRASILEIRA DE DÉFICIT DE ATENÇÃO, 2017)
}

Os professores devem conhecer sobre o TDAH, ter jogo de cintura e flexibilidade para ajudar o aluno TDAH. A informação é o passo mais importante para entender como funciona a cabeça destas crianças. Não cabe ao professor diagnosticar o TDAH, mas, caso perceba sintomas característicos em algum aluno, deve orientar a família a procurar ajuda. Quanto antes for instituído o tratamento médico e psicoterápico menos dificuldades ele terá em sua vida escolar, que se refletirão na vida adulta (SILVA, 2009). 
Entretanto, a prática tem mostrado que o sistema educacional ainda está bastante estratificado, e os professores encontram dificuldades, às vezes insuperáveis, para fazer as adaptações que se fazem necessárias para atender o aluno com TDAH. O professor deve, primeiramente, entender que o aluno não é um problema, mas que ele tem um problema; que não é consequência da falta de educação e/ou de um "déficit" intelectual, mas que compromete tanto a conduta quanto o rendimento acadêmico. O mais importante é que o professor se permita ficar intrigado, curioso, que veja neste aluno uma oportunidade para aprender, porque "ler" um aluno deveria ser um paixão em permanente construção para o docente (ROHDE \& MATTOS, 2003).

\subsection{FAMÍLIA, ESCOLA E A CRIANÇA COM TDAH}

Os pais devem deter conhecimento sobre o TDAH, a aceitação do problema influencia na qualidade dos investimentos que os pais irão realizar no auxilio e facilitação da vida de seus filhos. É imprescindível a aceitação dos pais diante das dificuldades de seus filhos de modo que eles possam assumir e cumprir o desafiante papel no progresso da criança (ARAÚJO, 2008).

Estudos indicam alto nível de estresse para os pais no acompanhamento de crianças na faixa dos três aos seis anos de idade. Parece diminuir posteriormente, mas é sempre maior quando comparado ao de pais de crianças controle. Além disso, o estresse daqueles pais é ainda maior quando existe presença de comorbidade com transtorno desafiador de oposição. Estudos realizados com pais destas crianças indicam que estes sentem maior insatisfação com seus papéis parentais. As mães têm vulnerabilidade aumentada para depressão e há maior consumo familiar de álcool em função do estresse (DESIDÉRIO \& MIYAZAKI, 2007).

Escola e família trabalhando em cooperação aumentam a probabilidade da criança ter uma experiência de vida escolar bem-sucedida. A criança com TDAH possui dificuldades as quais os pais e a escola precisam trabalhar unidos para que esse aluno possa alcançar sucesso. Podemos compreender isso quando Cavalcante afirma que "A colaboração entre pais e escola melhora o ambiente escolar e transforma a experiência educacional dos alunos numa vivência mais significativa" (CAVALCANTE, 1998).

É importante existir uma comunicação dos pais com a coordenação da escola para entender como a instituição lida com alunos com TDAH, e se os professores contam com orientações específicas para auxiliar o processo de aprendizagem de crianças que possuam déficit de atenção e hiperatividade. Quando a criança recebe um apoio, ela consegue desenvolver suas atividades, mesmo tendo suas limitações (SILVA, 2009).

Para Cunha (2007) a comunicação frequente entre a escola e a família é um fator importante para garantir esse relacionamento, para que tanto professores como pais possam trocar experiências 
relevantes para as horas difíceis. Saber o que está se passando durante o tempo que a criança está no outro ambiente ajuda a compor o quadro real da situação, e esse confiar no outro é que realmente estabelece a parceria.

Assim, o presente estudo tem por objetivo levantar fatores que levam as crianças com TDAH a não aprenderam na escola.

\section{MÉTODO E CASUÍSTICA}

Trata-se de um estudo longitudinal retrospectivo do tipo coorte histórico, que utiliza a revisão de prontuários guardados em arquivos, e esta pesquisa foi aprovada pelo Comitê de Ética e Pesquisa CEP da Faculdades Integradas Padre Albino - FAMECA sob PARECER CONSUBSTANCIADO DO CEP n ${ }^{\circ} 3.486 .315$.

\subsection{AMOSTRA}

O universo amostral da pesquisa foi composto de um total de 100 prontuários multidisciplinares de estudantes da Escola Municipal de Ensino Fundamental "Faride Aborihan", da cidade de Marapoama, estado de São Paulo, Brasil, dos anos de 2017 a junho de 2019. Os prontuários estavam alocados no Serviço de Arquivo da referida escola e neles constam as informações de atendimento de alunos que foram diagnosticados com TDAH e foram atendidos por equipe multidisciplinar.

\subsection{VARIÁVEIS}

As variáveis foram definidas de acordo com os dados pessoais e socioeconômicos previstos na primeira parte da coleta de dados sendo composta de variáveis continuas e variáveis discretas. O restante das variáveis especificas foram definidas de acordo com os dados encontrado nos prontuários.

As variáveis independentes foram: gênero, idade, etnia, estado civil dos pais, renda familiar, localidade de residência e com quem reside.

As variáveis dependentes foram: se os pais apresentam histórico/situação de drogadicção, histórico de violência doméstica, reprovações escolares (em caso positivo quantas, séries em que ocorreram as reprovações, em que disciplinas, se os pais estavam cientes em todos os casos de reprovação escolar), série regular em que está matriculado atualmente, se estudou sempre na mesma escola, se houve expulsões escolares, os comportamentos observáveis do cotidiano escolar, início dos sinais e sintomas de TDAH (ano escolar), disciplinas que apresenta maior dificuldade, situação do desempenho escolar do aluno e diagnóstico médico confirmado de TDAH. 


\subsection{DESENHO DO ESTUDO}

Os prontuários foram analisados individualmente um a um e para o registro e organização dos dados. As unidades de análise foram separadas e dividas em três partes: dados pessoais e socioeconômicos, dados de formação educacional e dados específicos contendo as respostas das questões dicotômicas de resposta única.

A unidade de analise utilizada foi para objeto da avaliação estratégia absoluta e comparativa. A análise descritiva incluiu frequência absoluta e relativa para variáveis categóricas, tabelas e gráficos utilizando para o tratamento estatístico o software IBM-SPSS Estatístics versão 24 (IBM Corporation, $N Y, U S A)$.

\section{RESULTADOS}

\subsection{TAMANHO FINAL DA AMOSTRA}

Neste estudo incialmente se propôs investigar 100 prontuários, porém 51 prontuários não apresentavam condições para inclusão na pesquisa por falta de preenchimento de dados corretos, prontuários que estavam incompletos ou faltavam dados consistentes e outros prontuários que não se enquadravam nos requisitos da pesquisa. Assim de 100 prontuários, apenas 49 (49\%) prontuários foram incluídos nesta pesquisa.

\subsection{VARIÁVEIS INDEPENDENTES}

Dos 49 prontuários pesquisados 31 (63.2\%) eram de crianças do sexo masculino e 18 (36,7\%) eram do sexo feminino. Assim nesta pesquisa ficou evidente que mais crianças do sexo masculinos apresentavam diagnóstico do TDAH. Quanto à idade das crianças que foram diagnosticadas com TDAH e atendidas, há uma enorme variedade e amplitudes de idades, sendo a maior idade 17 anos, e as menores idades na faixa dos 6 anos. Com relação à etnia a grande maioria das crianças $36(73,4 \%)$ eram brancas, e somente $13(26,5 \%)$ eram pardas e não se constatou a presença de crianças negras, índias ou nipônicas. Com relação ao número de irmãos 16 possuem apenas um irmão (33\%), 11 $(22,45 \%)$ nenhum irmão. Também se buscou saber se algumas crianças desta pesquisa foi adotada, e se constatou que $47(95,9 \%)$ são filhos biológicos e somente $2(4,1 \%)$ apresentam histórico de adoção. No que tange à existência de uma patologia de base se constatou que em 48 (98\%) prontuários não constava nenhuma patologia de base e apenas uma criança tinha o diagnóstico confirmado de Síndrome Fetal Alcoólica (Código Internacional de Doenças Q86.0).

Com relação ao estado civil dos pais $28(57,1 \%)$ são casados e 21(42,8\%) são separados e na identificação de quem são os atuais responsáveis pelo menor e com quem este reside a pesquisa 
identificou que há uma grande pluralidade, porém com predomínio $(28$ - 57,1\%) dos que residem com os pais biológicos.

Com relação se há pais em pena de reclusão 45 (91,8\%) dos pais não estão em pena de reclusão, $4(8,2 \%)$ estão, sendo o motivo da reclusão o furto. Ao se levantar o histórico e situação de drogadição do pai, constatou-se que $35(71,4 \%)$ dos pais não apresentam histórico de drogadição e $11(22,4 \%)$ dos pais apresentam histórico de drogadição. Segundo o apurado na pesquisa os pais envolvidos com drogadição o estão desde a adolescência sendo o tipo de droga mais prevalente o álcool. Quanto ao envolvimento da mãe em situação de drogadição se constatou que $41(83,6 \%)$ não apresentam histórico de drogadição, 5 (10,2\%) apresentam envolvimento com drogadição desde a infância ou adolescência. Quanto ao tipo drogas mais prevalentes entre as mães estavam (4 - 8,2\%), apenas drogas ilícitas (3 6,1\%) e o álcool acompanhado de drogas ilícitas (1-2\%).

$\mathrm{Na}$ investigação do histórico de violência doméstica se constatou que em 40 (81,6\%) não há relatos de violência doméstica, porém em 9 (18,3\%) há relatos de violência doméstica em lares onde as crianças são portadoras de TDAH.

Dos 49 prontuários investigados de crianças com TDAH 12 (24,4\%) residem na zona rural e 37 $(75,5 \%)$ na zona urbana. Nesta pesquisa se constatou que 49 (100\%) dos lares possuem uma renda familiar de 1 a 3 salários mínimos.

Apesar do histórico de TDAH das crianças foi constatado que 43 (87,7\%) das mesmas nunca reprovaram e somente 6 (12.2\%) apresentaram histórico de reprovações. Das $6(12,2 \%)$ crianças que reprovaram 4 reprovaram 1 único ano e $2 \mathrm{em} 2$ anos. As séries em que ocorreram as reprovações podem ser visualizadas no gráfico 4. Quanto à questão se os pais estavam cientes da reprovação dos filhos, 6 $(100 \%)$ estavam.

As reprovações ocorreram por três motivos básicos: 2 por faltas excessivas, 2 em duas matérias principais (Português e Matemática) e 1 apresentou um desempenho ruim em todas as matérias, o que culminou em reprovação.

No momento da coleta de dados os 49 anos alunos pesquisados portadores de TDAH estavam distribuídos em várias series do ensino fundamental e médio.

Quando aferido se os incluídos na pesquisa sempre estudaram na mesma escola 30 (61.2\%) sempre estudaram na mesma escola enquanto que 19 (38.7\%) vieram de outras escolas. Os alunos desta pesquisa, embora portadores de TDAH, nunca foram expulsos de nenhuma escola que frequentaram conforme verificado nos prontuários pesquisados.

Quanto ao desempenho escolar geral 37 (75,5\%) apresentavam desempenho fraco, $9(18,4 \%)$ regular e $2(4,1 \%)$ fraco. As matérias que apresentam maior dificuldade eram a português e matemática associadas (44 - 89,8\%), apenas português (4 - 8,2\%) e apenas matemática (1 - 3\%). O lapso temporal 
entre o diagnóstico médico de TDHA e a coleta de dados nos prontuários, em meses, variaram entre 6 a 108 meses, com predomínio de 36 meses (18 - 37\%), seguido de 24 meses (11 - 22,4\%).

\subsection{VARIÁVEIS DEPENDENTES}

Dados dos comportamentos observáveis do cotidiano escolar especificamente relacionados aos sinais e sintomas do TDAH e critérios de diagnóstico (DSM-5, 2014) nas crianças pesquisadas podem ser observados nos gráficos 1 a 4.

Gráfico 1: Frequência dos comportamentos observáveis do cotidiano escolar, relacionados aos sinais e sintomas do TDAH e critérios de diagnóstico - Critérios de desatenção $(n=49,2019)$

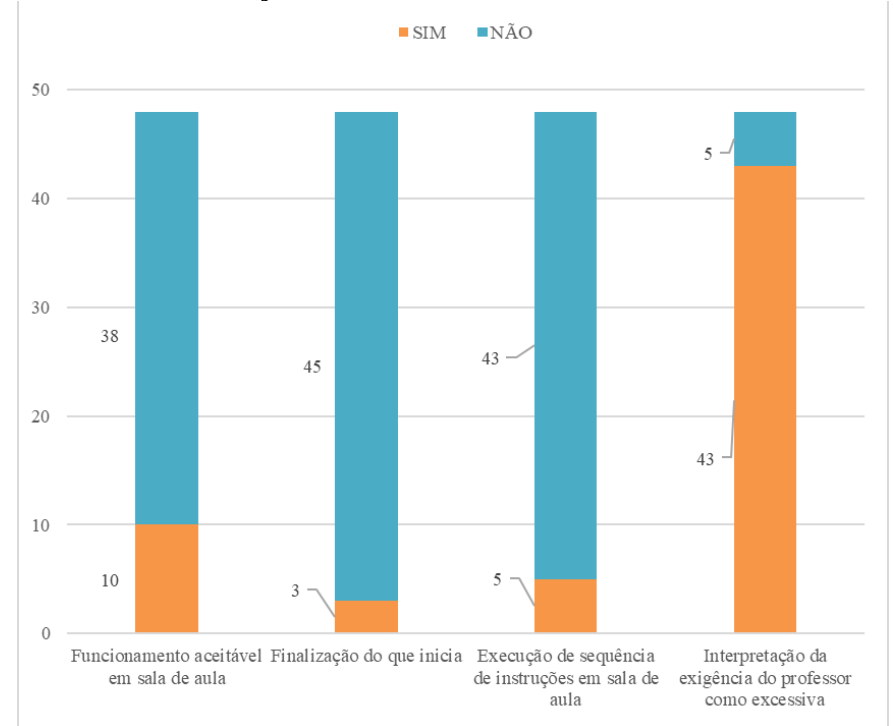

Fonte: Dados dos autores (2019).

Gráfico 2: Frequência dos comportamentos observáveis do cotidiano escolar, relacionados aos sinais e sintomas do TDAH e critérios de diagnóstico - Critérios de hiperatividade e impulsividade $(n=49,2019)$

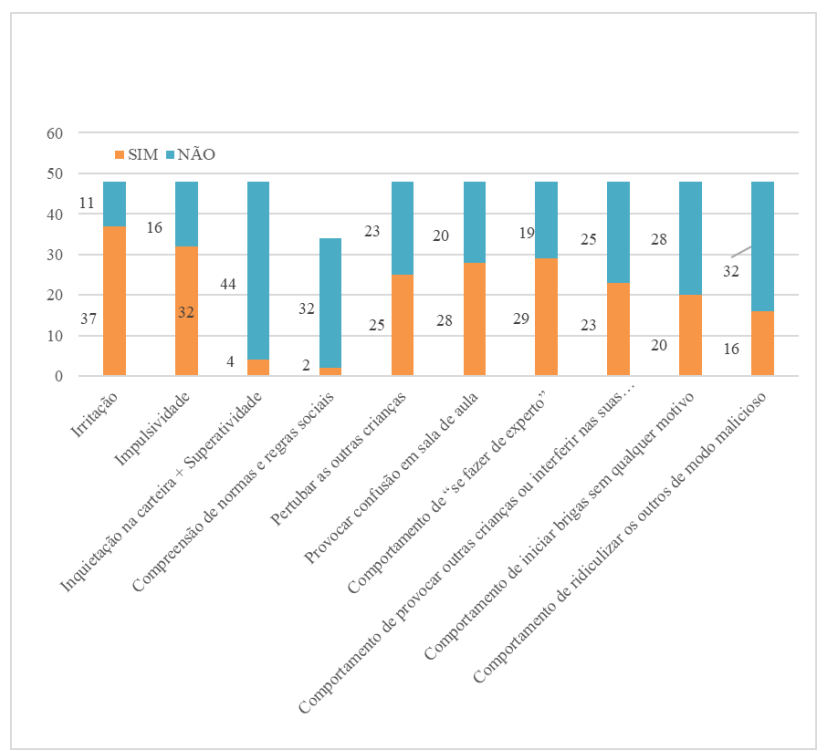

Fonte: Dados dos autores (2019). 


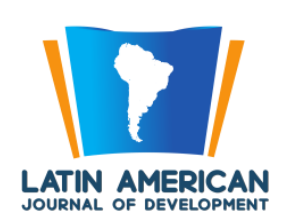

Gráfico 3: Frequência dos comportamentos observáveis do cotidiano escolar, relacionados aos sinais e sintomas do TDAH, evidenciando prejuízo no funcionamento social $(\mathrm{n}=49,2019)$

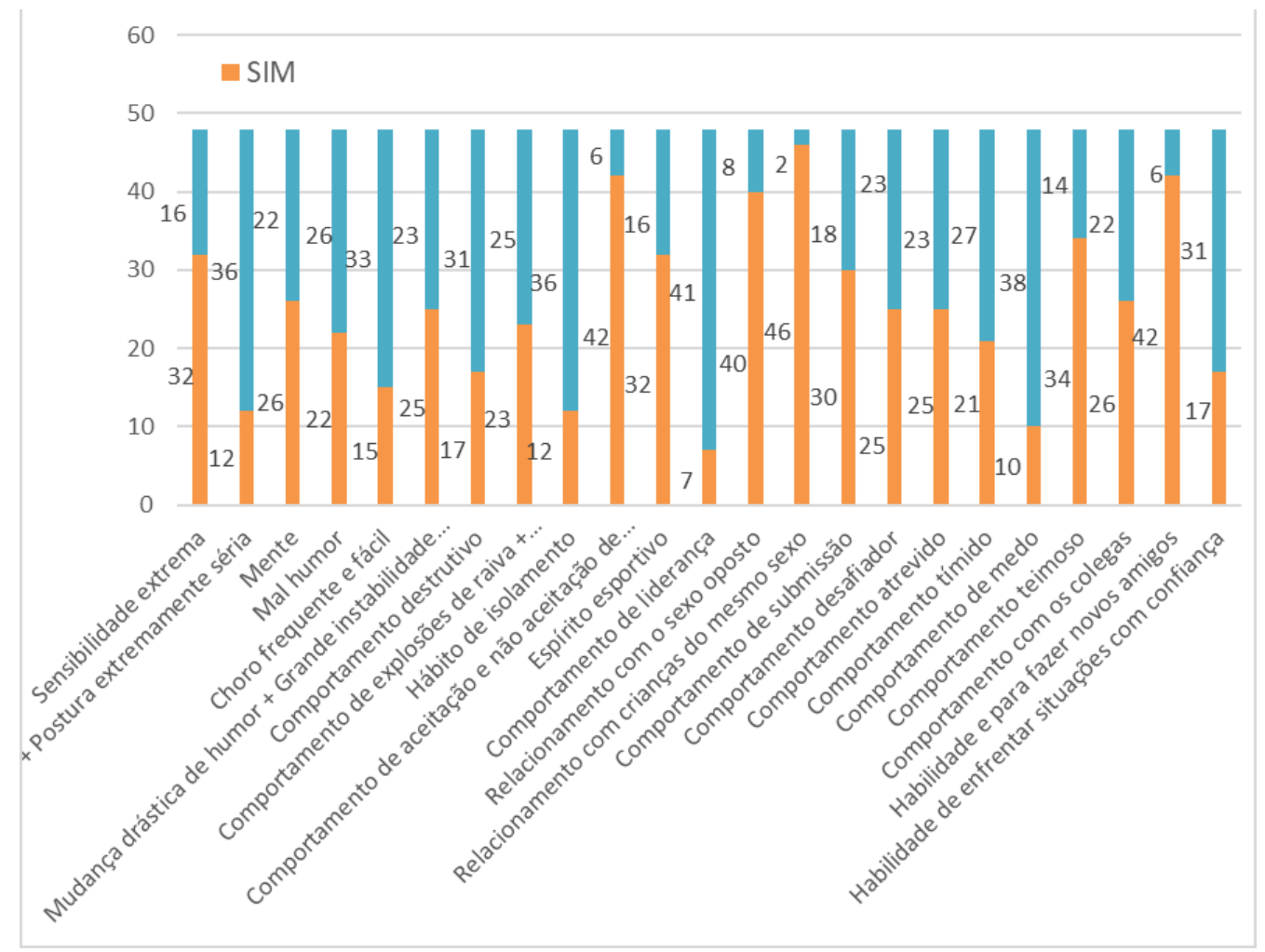

Fonte: Dados dos autores (2019).

Gráfico 4: Frequência dos comportamentos observáveis do cotidiano escolar, relacionados aos sinais e sintomas do TDAH, evidenciando prejuízo no funcionamento escolar $(n=49,2019)$

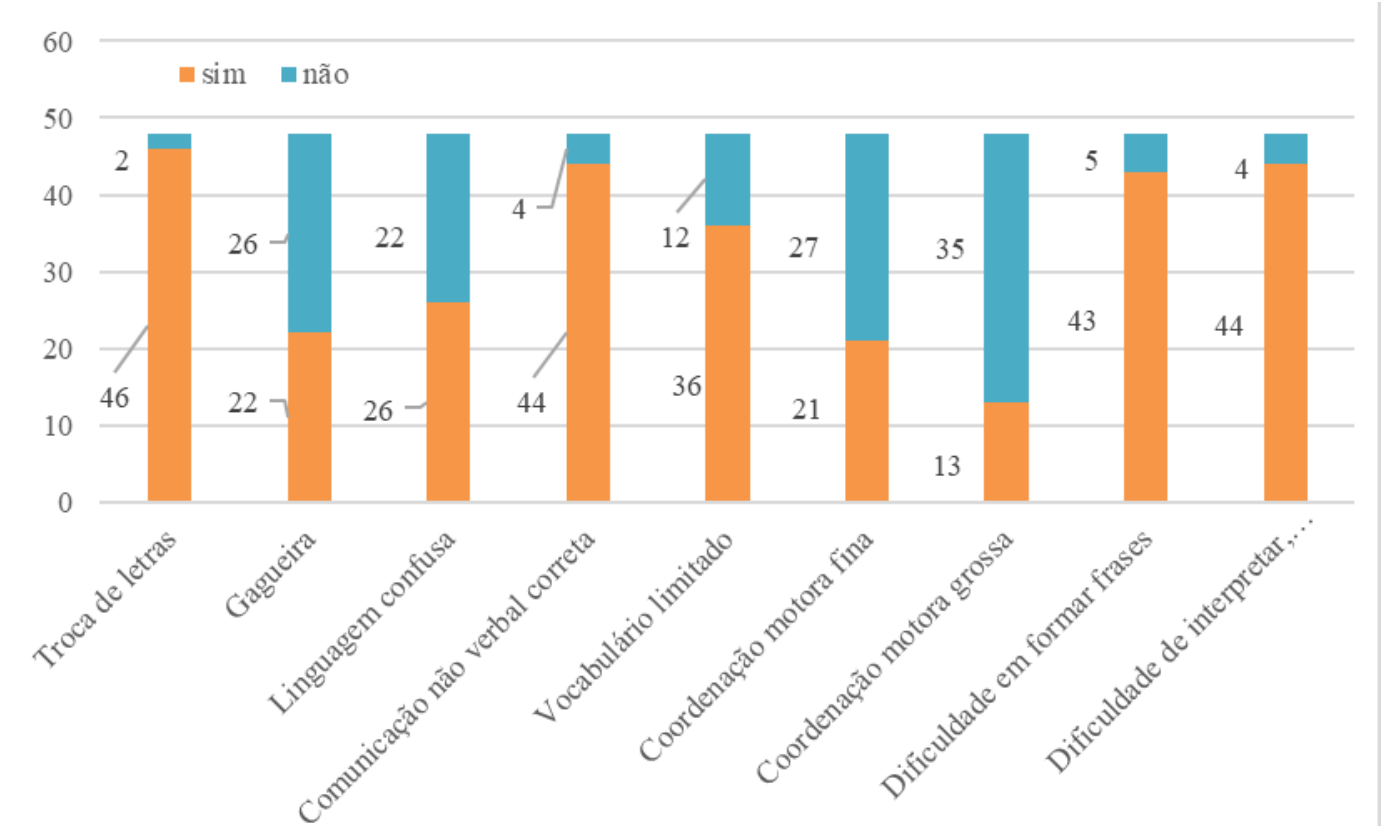

Fonte: Dados dos autores (2019). 


\section{DISCUSSÃO}

As pesquisas revelam que a prevalência do TDAH é maior entre os meninos do que entre as meninas, sendo uma proporção de 2:1 nas amostras populacionais e 9:1 nas amostras clínicas (ROHDE \& HALPERN, 2004), dado corroborado no presente estudo. Umas das justificativas apresentadas para esse fato é baseada no perfil psicossocial das meninas que geralmente é desatento e não apresenta outros sintomas, sendo menos incômodo para a família e para a escola, tendo como consequência um menor número de encaminhamentos para tratamento (FOLQUITTO, 2009). Além disso, a maior proporção do transtorno em indivíduos do sexo masculino pode estar relacionada com o maior número de encaminhamentos de meninos pela imputação da hiperatividade ao seu comportamento típico (BENTO et al., 2019).

De acordo com a Associação Americana de Psiquiatria (2014) o TDHA, considerado um transtorno do neurodesenvolvimento, surge antes dos sete anos de idade. $\mathrm{O}$ fato dos portadores de TDAH serem diagnosticados principalmente no período escolar está relacionado com a maior evidência dos sinais durante o ingresso das crianças nas atividades escolares, pois a partir desse momento as dificuldades de relacionamento com professores e colegas tornam-se notórias, uma vez que no período escolar a criança amplia o seu sistema social - do núcleo familiar para o escolar e passa a relacionar-se com colegas e professores (ARAÚJO \& SILVA, 2004).

Os fatores etiológicos dessa patologia ainda são desconhecidos, no entanto, supõe-se que apresenta base neurológica, sendo fortemente influenciada pela condição psíquica e do contexto familiar do paciente. Muitos estudos demonstram que, apesar de não ser a causa do desenvolvimento do TDAH, em crianças com predisposição neurobiológica a exposição a um contexto familiar conturbado atua como um fator de risco que pode desencadear a manifestação dos sintomas e alterar o decorrer do transtorno (CARLSON et al., 1995; BENTO et al., 2019). No Brasil um estudo revelou que em crianças expostas a confronto conjugal constante apresentam um risco 11,66 vezes maior de ser diagnosticada com o transtorno (VASCONCELOS et al., 2005). Ainda de acordo com a linha de pensamento de Rohde \& Benczik (2009), um estilo parental muito permissivo pode ser consequência e não causa do transtorno, características familiares tais como: funcionamento familiar caótico, alto grau de discórdia conjugal; baixa instrução materna; famílias com nível socioeconômico mais baixo; famílias com apenas um dos pais ou responsáveis, ou que o pai abandona a família, elementos encontrados na presente investigação. Outro dados da literatura também mostram relação na disfunção familiar e no TDAH, onde a disfuncionalidade na dinâmica familiar dentro de casa está associada à presença de sintomas do distúrbio (LÓPEZ SANTIAGO, 2020), corroborados pelo presente estudo. No que tange à religiosidade, dado não levantado nesta pesquisa, alunos que relatam não professar nenhuma religião têm maior disfunção familiar do que estudantes cristãos e os estudantes que não 
professam religião têm maiores dificuldades de atenção em relação aos católicos (LÓPEZ SANTIAGO, 2020).

A literatura relata chances de até 3 vezes maiores de reprovação (PASTURA et al., 2005) dado este que não se coaduna com os encontrados aqui (6 casos de reprovação, 12.2\%), mas reiteremos a questão da progressão continuada existente em nosso sistema educacional vigente. No que se refere ao desempenho escolar inferior da criança com TDAH quando comparada com a criança sem TDAH, salienta-se que o desempenho prático-produtivo envolvido no ato de ler e escrever, podem ser comprometidos com alterações neurofuncionais nas regiões cerebrais responsáveis pela entrada, processamento e execução da informação, podendo afetar as crianças com TDAH (OKUDA et al., 2011). Essas crianças têm pouca persistência de esforço para as tarefas e baixa atenção sustentada, o que justifica nossos dados de predominância de um desempenho escolar fraco (37,75,5\%). No entanto, esse problema normalmente surge quando a mesma é atribuída atividades aborrecidas, tediosas, prolongadas ou repetitivas que não têm apelo intrínseco a ela (BARKLEY, 2006). Contudo Moura et al. (2019) mostraram em sua amostra que motivação intrínseca e motivação total não se relacionaram com desempenho escolar. Pastura et al. (2005) ao colocar que a necessidade de $50 \%$ das crianças diagnosticadas com TDHA precisarem de aulas de reforço em leitura e aritmética, endossam nossos resultados de que 44 crianças $(89,8 \%)$ tem mais dificuldade em Português e Matemática. É importante destacar que fatores como a falta de atenção e os atrasos motores presentes nas crianças com dificuldades de aprendizagem podem estar associados ao insucesso nas atividades escolares. (MEDINA-PAPST \& MARQUES, 2010) Cada vez que um novo gesto motor é aprendido, ativa áreas cerebrais responsáveis pela atenção e raciocínio, estimulando diversas áreas cerebrais responsáveis também pelas aprendizagens prioritariamente cognitivas, como a leitura, a escrita e a aritmética (FITTS, 1967).

Crianças com TDAH tem dificuldades para modular e autorregular seus níveis de motivação intrínseca, indicando uma disfunção primária do sistema de recompensa que implica na maior necessidade de reforço positivo por parte do mediador ou professor para a execução de tarefas escolares e há relação entre motivação extrínseca e o desempenho em tarefas de leitura, escrita e aritmética (MOURA et al., 2019). Ainda segundo a Associação Americana de Psiquiatria (2014) o TDHA apresenta três principais sintomas: a desatenção, a hiperatividade e a impulsividade. Os indivíduos com TDAH sentem grande dificuldade em manterem-se engajados em tarefas que não possuem recompensa imediata e apresentam alto grau de aversão à demora (MIRANDA et al., 2013). Mesmo diante da possibilidade de obter gratificações mais significativas no futuro, eles tendem a não conseguir autorregular seu comportamento e acabam preferindo as recompensas imediatas, mesmos quando essas são menores. Barkley (2008) e Montiel et al. (2014) remetem tais comportamentos a prejuízos nas 
funções executivas, especificamente no controle inibitório, que é a capacidade de controlar um forte impulso em prol de um comportamento mais adequado à situação (DIAMOND \& LEE, 2011). As características comportamentais supracitadas em combinação com os déficits atencionais comuns ao TDAH são as principais causas de prejuízos no processo de aprendizagem (COSTA et al., 2014) ao promover a desatenção observada através de comportamento do cotidiano escolar como o não funcionamento em sala de aula, a não finalização de tarefas que inicia e a não execução de sequências de instruções em sala de aula, considerando excessivas as exigências do professor. A resistência em permanecer sentado e quieto durante situações em que se espera que a criança permaneça dessa maneira demonstra claramente a hiperatividade e a dificuldade em esperar por sua vez, interromper as pessoas e falar de maneira precipitada, a impulsividade. Tonelotto e Gonçalves (2002) mostraram que as crianças com problemas de atenção, quando comparadas ao grupo sem os mesmos problemas, apresentavam percepção mais negativa de seu desempenho no contexto da sala de aula, percebiam os professores como menos simpáticos para com elas e eram mais citadas por seus colegas como rejeitadas e, na mesma proporção, menos citadas quando a questão era a aceitação. Da mesma forma, o estudo realizado por Capelatto et al. (2014) identificou que as crianças com TDAH se sentem mais culpadas, acreditam que fazem coisas mais erradas e apresentam autoestima negativa. Para os autores, as dificuldades nas funções de atenção e executivas afetam negativamente as performances nos trabalhos da escola e tarefas diárias, que por sua vez, podem impactar o desenvolvimento da autoestima e causar mais sentimento de culpa. Estes 2 estudos foram realizados com crianças brasileiras. Molina e Maglio (2013) trabalhando com crianças argentinas na mesma faixa etária, mostrou a mesma tendência dos estudos brasileiros, sendo que a autopercepção mais negativa foi relatada por crianças com TDAH quando da avaliação da sua competência acadêmica, aceitação social, comportamento e autoestima global. Essas mesmas crianças apresentaram ainda viés positivo, quando comparadas à percepção dos pais, nos domínios de competência acadêmica, social e de comportamento.

Tudo isso reitera que a criança com TDAH apresenta dificuldades de aprendizagem e de convívio social com seus pares, influenciando diretamente seu desempenho escolar. (PASTURA et al., 2005; CAPELINI et al., 2007) Para que ocorram mudanças positivas no mesmo as atividades precisam ser interessantes e estimulantes a todos os alunos, principalmente aos alunos que possuem dificuldades de atenção e baixo engajamento na atividade proposta. O professor precisa ser claro em suas explicações, podendo utilizar imagens e escrita como auxílio, sendo fundamental verificar a real compreensão do aluno na atividade (FARREL, 2008). Essas atividades devem ser lúdicas, pois são indispensáveis à prática educativa, contribuindo e enriquecendo o desenvolvimento intelectual das crianças (PIAGET, 1973). Dados na literatura mostram que o baixo desempenho na ação motora da criança com TDAH (AMÉRICO et al., 2016) reforçam as características do transtorno enfatizadas por 
estudiosos da área. (BARKLEY, 1997; BENCZIK, 2000; ROHDE et al., 2000; MOREIRA \& BARRETO, 2009; SANTOS \& VASCONCELOS, 2010) As crianças com TDAH possuem alternância constante de tarefas, relutância no engajamento de atividades complexas que exijam organização e regras, tolerância à espera, dificuldades em controlar a sua impulsividade e manter-se focado na tarefa, necessitando de recompensa imediata. Sendo assim, possivelmente o fato de a criança com TDAH analisada precisar esperar a sua vez para participar das atividades, bem como ter materiais diversificados na mesma tarefa contribuiu para que a mesma se dispersasse ou Os atrasos no desempenho motor deste estudo reforçam modificasse a atividade, inclusive se envolvendo em confusões e transitando entre outros espaços da aula. Os problemas de atenção podem influenciar nas habilidades motoras básicas (estabilizadoras, locomotoras e manipulativas fina e grossa) (CYPEL, 2000; AMÉRICO et al., 2016). Os alunos com TDAH tem uma tendência de emitir respostas rápidas, embora imprecisas (BARKLEY, 1997), bem como organização espacial, alinhamento e manutenção da postura corporal (RUBIO-GRILO et al., 2014), sendo que essa dificuldade de manutenção da postura pode ser determinante na capacidade de manter atenção nas atividades. As atitudes de engajamento demonstram que a criança com TDAH realiza a maioria das habilidades com dificuldades para se concentrar, refletindo consequentemente no atraso do seu desempenho nas habilidades propostas durante a aula. (AMÉRICO et al., 2016).

No que tange às interações sociais a maioria deles apresenta dificuldades para realização das atividades escolares em grupos e para entrar nas brincadeiras e dificuldades para fazer amigos fora do ambiente escolar o que implica em um número restrito de amigos e em isolamento social, o que se depreende de seus relatos de recusas dos amigos quando querem brincar juntos, e do desejo de terem mais amigos e de serem aceitos. Nas interações sociais com os adultos, é relatado que as mesmas também são permeadas por mais interações aversivas do que positivas, com a maioria das crianças relatando serem alvos de broncas e xingamentos. (ROCHA \& FERREIRA, 2018)

\section{IMPLICAÇÕES PARA A PRÁTICA}

É importante ressaltar que as crianças aprendem de forma integrada, as experiências de movimento de qualquer atividade, devem fazer conexão com outras áreas do conhecimento, como por exemplo, o pensamento associativo, dedutivo e abstrato para a aprendizagem da leitura, da linguagem escrita, da matemática, entre outros. Nesse sentido, salienta-se a importância da reflexão pedagógica dos professores, redimensionando o papel do educador e colocando o aprendiz, principalmente quando esse tem dificuldades de atenção e aprendizagem, no centro do processo de ensino-aprendizagem. Para que ocorra esse processo é fundamental que cada professor utilize diferentes propostas metodológicas, 
optando por aquelas que melhor se ajustem às necessidades dos aprendizes, ao contexto escolar e às convicções do próprio educador. (AMÉRICO et al., 2016)

O baixo desempenho escolar tem sido fortemente associado à apresentação de níveis mais baixos de motivação intrínseca (MARTINELLI \& GENARI, 2009; PAIVA \& BORUCHOVITCH, 2010; MARTINELLI, 2014). Baixos níveis de motivação intrínseca podem implicar em maior necessidade de recompensas externas, principalmente durante a execução de tarefas que demandam maior esforço cognitivo, como é o caso das tarefas escolares. Desta forma, esse resultado pode ajudar a pensar em estratégias de manejo para crianças com TDAH em sala de aula, como, por exemplo, o reforço positivo por parte do professor (FONSECA et al., 2012) já que quanto menor o desempenho nas tarefas de leitura, escrita e aritmética, maior o índice de motivação extrínseca (MOURA et al., 2019).

As dificuldades na sala de aula são desafios encontrados pela escola com vários alunos e é preciso buscar vencer esses desafios a partir de estratégias que visem atender as necessidades de cada um, com ênfase na aprendizagem, inclusive os diagnosticados com TDAH (MOURA et al., 2019).

\section{CONCLUSÕES}

Considerando que o TDAH é um transtorno que afeta o aluno, causa dificuldades na aprendizagem, gera insegurança e ansiedade, que é possível responsabilizar esse transtorno pelos comportamentos apresentados pelos estudantes no desenvolvimento cognitivo e intelectual, que as dificuldades no processo de ensino-aprendizagem em sala de aula podem ser vencidas quando o professor se propõe a confrontar os próprios saberes, atuações e práticas com novos conhecimentos e estratégias, visando um ensino de qualidade e que a forma de ensinar um aluno com TDAH demonstrase complexa e difícil é importante que se perceba o potencial que esse aluno poderá ou não desenvolver e que se tenha a capacidade de reconhecer a responsabilidade dele sobre o resultado. Para tanto o professor deve ter um equilíbrio emocional, ser criativo, e conhecer com propriedade o transtorno do aluno, pois, assim, terá mais facilidade para obter a participação desses educandos em sala de aula e é isso que apresenta a presente investigação: dados que mostram como se pode conhecer com propriedade o transtorno do aluno, obtidos dentro do contexto escolar, já que cabe à escola propiciar aos alunos com TDHA, aprendizagens significativas de acordo com suas potencialidades, procurando garantir a todos um ensino de qualidade, de forma inclusiva.

É primordial buscar constantemente conhecer mais acerca desse transtorno, tanto por parte dos profissionais da educação quanto da família, desde o diagnóstico até o tratamento, de forma a contribuir para oferecer, no âmbito escolar, um ensino significativo para os TDAHs. 


\section{REFERÊNCIAS}

AMERICAN PSYCHIATRIC ASSOCIATION. Manual Diagnóstico e Estatístico de Transtornos Mentais- DSM-5. Tradução: Maria Inês Corrêa Nascimento. 5. ed. Porto Alegre: Artmed, 2014.

POLANCZYK, G.V. et al. ADHD prevalence estimates across three decades: an updated systematic review and meta-regression analysis. International Journal of Epidemiology, v. 43, n. 2, p. 434-442, apr. 2014. https://doi.org.10.1093/ije/dyt261

SILVA, A. B. B. Mentes Inquietas TDAH: Desatenção, Hiperatividade e Impulsividade. Rio de Janeiro: Objetiva, 2009.

FARAONE, S. V. et al. Attention-deficit/hyperactivity disorder. Nature Reviews: Disease Primers, v. 1, p. 15020, aug. 2015. DOI: https: //doi.org.10.1038/nrdp.2015.20

THAPAR, A,; COOPER, M. Attention deficit hyperactivity disorder. Lancet, London, v. 387, n. 10024, p. 1240-1250, mar. 2016. DOI: https: //doi.org.10.1016/S0140-6736(15)00238-X

ROHDE, L. A. P.; BENCZIK, E. B. P. Transtorno de Déficit de Atenção: O que é? Como ajudar? Porto Alegre: Artmed, 2009.

GOLDSTEIN, S.; GOLDSTEIN, M. Hiperatividade: Como desenvolver a capacidade de atenção da criança. 13. ed. Campinas: Papirus, 2009.

SILVA, B. K. M. Família e a escola na aprendizagem da criança com TDAH: a necessidade de uma parceria ativa e produtiva. 2020. Monografia (Pedagogia) - Pontifícia Universidade Católica de Minas Gerais (PUC Minas), Belo Horizonte, 2020. Disponível em: http://periodicos.pucminas.br/index.php/pedagogiacao/article/view/11042. Acesso em: 9 abr. 2021 .

ASSOCIAÇÃO BRASILEIRA DO DÉFICIT DE ATENÇÃO (ABDA). Relação professor, escola, aluno e família. A educação unida para o sucesso! 2017. Disponível em: https://tdah.org.br/relacaoprofessor-escola-aluno-e-familia-a-educacao-unida-para-o-sucesso/. Acesso em: 9 abr. 2021.

ROHDE, L. A. P.; MATTOS, P. Princípios e práticas em transtornos de déficit de atenção/hiperatividade. Porto Alegre: Artmed, 2003.

ARAÚJO, F. L. C. Transtorno de Defícit de Atenção e Hiperatividade - TDAH. 2008 Monografia (Especialista em Psicopedagogia Institucional e Clínica) - Universidade Estadual Vale do Acaraú, Sobral, Ceará, 2008.

DESIDÉRIO, R. C. S.; MIYAZAKI, M. C. O. S. Transtorno de Déficit de Atenção / Hiperatividade (TDAH): orientações para a família. Psicologia Escolar e Educacional, Campinas, v. 11, n. 1, p. 165176, jan./jun. 2007. DOI: https://doi.org/10.1590/S1413-85572007000100018

CAVALCANTE, R. S. C. Colaboração entre pais e escola: educação abrangente. Psicologia Escolar e Educacional, Campinas, v. 2, n. 2, p. 153-160, mai./ago. 1998. DOI: https://doi.org/10.1590/S141385571998000200009

CUNHA, A. E. Afetividade na prática pedagógica: educação, TV e escola. Rio de Janeiro: Wak, 2007. 
ROHDE, L. A.; HALPERN, R. Recent advances on attention deficit/hyperactivity disorder. Jornal de Pediatria, Rio de Janeiro, v. 80, n. 2, p. 61-70, abr. 2004. Suplemento. DOI: https://doi.org/10.1590/S0021-75572004000300009

FOLQUITTO, C. T. F. Desenvolvimento psicológico e transtorno de déficit de atenção e hiperatividade (TDAH): a construção do pensamento operatório. 2009. Dissertação (Psicologia Escolar e do Desenvolvimento Humano) - Instituto de Psicologia da Universidade de São Paulo - USP, São Paulo, 2009. Dispoível em: https://www.teses.usp.br/teses/disponiveis/47/47131/tde-21032009095322/publico/camila_tarif_folquitto.pdf. Acesso em: 9 abr. 2021.

BENTO, L. A. et al. Crianças com Transtorno de Déficit de Atenção e Hiperatividade - TDAH: comparação do desempenho escolar dos alunos tratados e não tratados com metilfenidato. Revista UNINGÁ, Maringá, v. 56, n. 2, p. 151-159, jun. 2019. Disponível em: http://revista.uninga.br/index.php/uninga/article/view/779/1975. Acesso em: 9 abr. 2021.

ARAUJO, M.; SILVA, S. A. P. S. Comportamentos indicativos do transtorno de déficit de atenção e hiperatividade em crianças: alerta para pais e professores. Revista PIBIC, Niterói, v. 1, n 1, p. 55-64, jan./dez. 2004. Disponível em: http://www.unifieo.br/files/0218edfma.pdf. Acesso em: 9 abr. 2021.

CARLSON, E. A.; JACOBVITZ, D.; SROUFE, L. A. A developmental investigation of inattentiveness and hyperactivity. Child Development, Chicago, v. 66, n. 1, p. 37-54, feb. 1995. DOI: https://doi.org/10.1111/j.1467-8624.1995.tb00854.x

VASCONCELOS, M. M., et al. Contribuição dos fatores de risco psicossociais para o transtorno de déficit de atenção/hiperatividade. Arquivos de Neuro-psiquiatria, São Paulo, v. 63, n. 1, p. 68-74, mar. 2005. DOI: https://dx.doi.org/10.1590/S0004-282X2005000100013

LÓPEZ SANTIAGO, M. G. El TDAH con relación a la disfunción familiar en adolescentes de secundaria. 2020. Tese (Doutorado em Pedagogia) - Universidad de Ciencias y Artes de Chiapas, Chiapas: Tuxtla Gutiérrez, 2020.

PASTURA, G. M. C.; MATTOS, P.; ARAÚJO, A. P. Q. C. Desempenho escolar e transtorno do déficit de atenção e hiperatividade. Archives of Clinical Psychiatry, São Paulo, v. 32, n. 6, p. 324-329, nov./dez. 2005. DOI: https://dx.doi.org/10.1590/S0101-60832005000600003

OKUDA, P. M. M. et al. Coordenação motora fina de escolares com dislexia e transtorno do déficit de atenção e hiperatividade. Revista CEFAC, São Paulo, v. 13, n. 5, p. 876-885, set./out. 2011. DOI: https://dx.doi.org/10.1590/S1516-18462011005000048

BARKLEY, R. A. Attention déficit hyperactivity disorder: a handbook for diagnosis and treatment. New York: The Guilford Press, 2006.

MOURA, L. T.; SILVA, K. P. M.; SILVA, K. P. M. Alunos com TDAH (Transtorno de Déficit de Atenção e Hiperatividade): um desafio na sala de aula. Revista Eletrônica Acervo Saúde, n. 22, p. 1-7, abr. 2019. Suplemento. DOI: https://doi.org/10.25248/reas.e611.2019

MEDINA-PAPST, J.; MARQUES, I. Avaliação do desenvolvimento motor de crianças com dificuldades de aprendizagem. Revista Brasileira de Cineantropometria \& Desempenho Humano, Florianópolis, v. 12, n. 1, p. 36-42, jan./fev. 2010. DOI: http://dx.doi.org/10.5007/19800037.2010v12n1p36 
FITTS, P. M.; POSNER, M. I. Human performance. Belmont, CA: Brooks/Colemann, 1967.

MIRANDA, M.; RIZZUTTI, S.; MUSZKAT, M. Transtorno do Déficit de Atenção e Hiperatividade. In: MIRANDA, M.; MUSZKAT, M.; MELLO, C. B. Neuropsicologia do desenvolvimento: Transtornos do neurodesenvolvimento. Rio de Janeiro: Rubio, 2013, p. 31-60.

BARKLEY, R. A. Transtorno de Déficit de Atenção e Hiperatividade: Manual para Diagnóstico e Tratamento. 3. ed. Porto Alegre: Artmed, 2008.

MONTIEL, J. M. et al. Associações entre medidas de Funções Executivas e sintomas de desatenção e hiperatividade em crianças em idade escolar. Neuropsicologia Latinoamericana, Calle, v. 6, n. 1, p. 1321, jan. 2014. Disponível em: http://dx.doi.org/10.5579/rnl.2013.0158. Acesso em: 9 abr. 2021.

DIAMOND, A.; LEE, K. Interventions shown to aid executive function development in children 4 to 12 years old. Science, New York, v. 333, n. 6045, p. 959-964, aug. 2011. DOI: https://doi.org.10.1126/science.1204529

COSTA, D. S. et al. Neuropsicologia do transtorno de déficit de atenção/hiperatividades e outros transtornos externalizantes. In: Fuentes D., et al. Neuropsicologia: Teoria e Prática. 2. ed. Porto Alegre: Artmed, 2014, p. 166-182.

TONELOTTO, J. M. F.; GONÇALVES, V. M. G. Autopercepção de crianças desatentas no ambiente escolar. Estudos de Psicologia (Campinas), Campinas, v. 19, n. 3, p. 31-41, set./dez. 2002. DOI: https://doi.org/10.1590/S0103-166X2002000300004

CAPELATTO, I. V., et al. Cognitive functions, self-esteem and self-concept of children with attention deficit and hyperactivity disorder. Psicologia: Reflexão e Crítica, Porto Alegre, v. 27, n. 2, p. 331-340, abr./jun. 2014. DOI: http://dx.doi.org/10.1590/1678-7153.201427214

MOLINA, M. F.; MAGLIO, A. L. Características del autoconcepto y el ajuste en las autopercepciones de los niños con transtorno por déficit de atención con hiperactividad de Buenos Aires. Cuadernos de Neuropsicologia, Santiago, v. 7, n. 2, p. 50-71, dez. 2013.

Disponível em: http://pepsic.bvsalud.org/pdf/cnps/v7n2/n2a04.pdf. Acesso em: 9 abr. 2021.

CAPELLINI, A. S. et al. Desempenho de escolares bons leitores, com dislexia e com transtorno do déficit de atenção e hiperatividade em nomeação automática rápida. Revista da Sociedade Brasileira de Fonoaudiologia, São Paulo, v. 12, n. 2, p. 114-119. abr./jun 2007. DOI: https://dx.doi.org/10.1590/S1516-80342007000200008

FARREL, M. Dificuldades de relacionamento pessoal, social e emocional: guia do professor. Porto Alegre: Artmed, 2008.

PIAGET, J. A formação do símbolo da criança. 3. ed. Rio de Janeiro: Editora Zahar, 1973.

AMÉRICO, C. D. P.; KAPPEL, N. R. R.; BARZEL, A. A criança com TDAH: análise do desempenho escolar e engajamento motor. Cinergis, Santa Cruz do Sul, v. 17, n. 2, p. 150-156, abr./jun. 2016. DOI: http://dx.doi.org/10.17058/cinergis.v17i2.7747 
BARKLEY, R. A. Behavioral inhibition, sustained attention, and executive functions: Constructing a unifying theory of ADHD. Psychological Bulletin, Washington, v. 121, v. 1, p. 65-94, jan.1997. DOI: https://doi.org.10.1037/0033-2909.121.1.65

BENCZIK, E. B. P. Transtorno do déficit de atenção/hiperatividade: atualização diagnóstica e terapêutica: características, avaliação, diagnóstico e tratamento: um guia para profissionais. São Paulo: Casa do Psicólogo, 2000.

ROHDE, L. A. et al. Transtorno de déficit de atenção/Hiperatividade. Brazilian Journal of Psychiatry, São Paulo, v. 22, p. 7-11, dec. 2000. Suplemento 2. DOI: https://doi.org/10.1590/S151644462000000600003

MOREIRA, S. C.; BARRETO, M. A. M. Transtorno de déficit de atenção e hiperatividade: conhecendo para intervir. Revista Práxis, Volta Redonda, v. 1, n. 2, p. 65-70, abr./jun. 2009. Disponível em: http://revistas.unifoa.edu.br/index.php/praxis/article/view/1123/1013. Acesso em: 9 abr. 2021.

SANTOS, L. F.; VASCONCELOS, L. A. Transtorno do Déficit de Atenção e Hiperatividade em Crianças: Uma Revisão Interdisciplinar. Psicologia: Teoria e Pesquisa, Brasília, v. 26, n. 4, p. 717-724, out./dez. 2010. DOI: https://doi.org/10.1590/S0102-37722010000400015

CYPEL, S. A criança com déficit de atenção e hiperatividade: atualização para pais, professores e profissionais da saúde. São Paulo: Lemos, 2000.

RUBIO-GRILO, M. H.; SALAZAR-TORRES, L. J.; ROJAS-FAJARDO, A. Habilidades motoras y de procedimiento que interfieren en la vida académica habitual de un grupo de Estudiantes con signos y síntomas de TDAH. Revista Colombiana de Psiquiatria, Bogotá, v. 43, n. 1, p. 18-24, mar. 2014. DOI: https://doi.org/10.1016/S0034-7450(14)70038-1

ROCHA, M. M.; FERREIRA, M. C B. Autopercepção de um grupo de crianças com diagnóstico de TDAH: implicações educacionais. Revista FAED, Cáceres, v. 30, n. 2, 171-191 jul./dez, 2018. Disponível em: https://periodicos.unemat.br/index.php/ppgedu/article/view/3883/3078. Acesso em: 9 abr. 2021.

MARTINELLI, S. C.; GENARI, C. H. M. Relações entre desempenho escolar e orientações motivacionais. Estudos de Psicologia (Natal), Natal, v. 14 n. 1, p. 13-21, jan/abr. $2009 . \quad$ DOI: http://dx.doi.org/10.1590/S1413-294X2009000100003

PAIVA, M. L. M. F.; BORUCHOVITCH, E. Orientações motivacionais, crenças educacionais e desempenho escolar de estudantes do ensino fundamental. Psicologia em Estudo, Maringá, v. 15, n. 2, p. 381-389, abr./jun. 2010. DOI: http://dx.doi.org/10.1590/S1413-73722010000200017

MARTINELLI, S. C. Um estudo sobre desempenho escolar e motivação de crianças. Educar em Revista, Curitiba, n. 53, 201-216, jul./set. 2014. DOI: http://dx.doi.org/10.1590/0104-4060.27122

FONSECA, M. F. B. C.; MUSZKAT, M.; RIZZUTTI, S. Transtorno do déficit de atenção e hiperatividade na escola: mediação psicopedagógica. Revista Psicopedagia, São Paulo. v. 29, n. 90, p. 330-339, set./dez. 2012. Disponível em: http://pepsic.bvsalud.org/pdf/psicoped/v29n90/07.pdf. Acesso em: 9 abr. 2021. 